\title{
1 Experimental investigation of the effects of \\ 2 aggregate size distribution on the fracture \\ 3 behaviour of high strength concrete
}

\author{
4 1. A. P. N. Siregar \\ 5 Civil Engineering Department, Tadulako University, Indonesia. \\ $6 \quad$ Email : $\quad$ a.siregar@surrey.ac.uk \\ 8 2. M. Imran Rafiq (corresponding author) \\ 9 School of Environment and Technology, University of Brighton, United Kingdom. \\ 10 Email : m.rafiq@brighton.ac.uk \\ 11 Tel: : $\quad+44-1273-642163$ \\ 12 3. M. Mulheron \\ 13 Department of Civil and Environmental Engineering, University of Surrey, United \\ 14 Kingdom. \\ 15 Email : m.mulheron@surrey.ac.uk
}

17 Abstract: This paper examines the influence of different aggregate size distributions on the 18 fracture behaviour of high strength concrete. Three-point bend test was performed on 63 notched

19 beams casted using three aggregate size distributions and two water to binder ratios. The total 20 fracture energy, $G_{F}$, and critical stress intensity factor, $K_{I C}$, were used to determine the fracture 21 characteristic of concrete. The results show that the values of $G_{F}$ decrease substantially with 22 increasing coarseness of aggregate grain structure, $\lambda$. Values of $K_{I C}$ also decreased but 23 demonstrated only limited dependence on $\lambda$. In contrast, reducing the total w/b ratio substantially

24 increases the value of $K_{I C}$ but had no measurable effect on $G_{F}$.

25 Keywords Aggregate size distribution, Aggregate grading, Fracture energy, 26 Stress intensity factors, size effect;

Highlights:

- Aggregate size distribution affects the fracture behavior of high strength concrete

- Fracture energy and stress intensity factors measured for 63 notched beams 
- Strong dependence of fracture energy upon aggregate size distribution.

- Limited dependence of stress intensity factor upon aggregate size distribution.

- Reducing the water to binder ratio increases the stress intensity factor

- Reducing the water to binder ratio have no measurable effect on the fracture energy.

- Maximum value of fracture energy for high strength concrete is limited by the strength of aggregates used.

\section{$40 \quad 1$ Introduction}

41 Concrete is widely used in the construction of buildings, bridges and other

42 infrastructure around the world. Its use is driven by its flexibility of form, the

43 relative simplicity of manufacture and the widespread availability of both binder

44 materials, such as Portland cement, and inert, graded, granular aggregates. As a

45 particulate composite material, the physical and mechanical properties of

46 hardened concrete are strongly influenced by both its constituent materials and the

47 proportions in which they are combined. The aggregate typically occupies more

48 than $70 \%$ of the volume of a concrete mix and plays an important role in

49 determining the physical properties and mechanical behaviour of both the fresh

50 and hardened material (Chen and Liu 2004). The interactions that occur at the

51 interface between the aggregate particles and the cement paste which surrounds

52 and binds them influences many of the properties of hardened concrete, including

53 strength, stiffness and fracture toughness. Historically, normal strength concrete,

54 with a compressive strength of less than $50 \mathrm{MPa}$, has been used in the

55 construction of plain, reinforced and prestressed concrete structures (Comitte

56 Euro-International du Beton 2010). However, over the past 30 years, there has

57 been increasing use of, and reliance on, so-called high-strength concrete for the

58 creation of ultra-high-rise buildings and long-span bridges (Wolinski et al. 1987; 
59 American Concrete Institute 2010). High-strength concretes routinely have

60 compressive strengths in the range 60-90 MPa although much higher values can

61 be achieved. This requires good mix design, the appropriate selection of

62 constituent materials combined with the use of specialised admixtures. As a

63 consequence, there is significant interest in understanding the mechanisms that

64 govern the failure behaviour of such high-strength ceramic composites.

65

66 Whilst the fracture resistance of Portland cement concrete is known to be

67 dependent on its compressive strength and water/binder ratio, w/b, other

68 parameters such as the size, shape, surface texture, and volume fraction of the

69 aggregate have also been found to influence the fracture mechanics parameters of

70 hardened concrete (Hillerborg 1985; Wolinski et al. 1987; Mihashi et al. 1991;

71 Zhou et al. 1995; Wu et al. 2001; Xiao et al. 2004; Elices and Rocco 2008; Ince

72 and Alyamac 2008; Königsberger et al. 2014). In normal strength concrete both

73 the fracture toughness, i.e. the critical stress intensity factor, $K_{I C}$, and the fracture

74 energy, $G_{F}$, of concrete have been found to increase with the compressive strength

75 of the concrete (Ince and Alyamac 2008), and the maximum aggregate size

76 (Hillerborg 1985; Wolinski 1987; Mihashi 1991) and volume fraction of the

77 aggregate (Amparano and Roh 2000). Similar behavior have also been reported

78 for the self compacted concrete (Karamloo et al. 2016). However, aggregate type,

79 and associated particle shape and surface texture has been found to have little

80 effect on the facture energy of normal strength concrete (Wu et al. 2001; Xiao et

81 al. 2004).

82

83 The compressive strength of high strength concrete also affects the measured 84 values of both $K_{I C}$ and $G_{F}$ (Wu et al. 2001; Xiao et al. 2004), which increases as 
85 the maximum aggregate size increases (Chen and Liu 2004). Unlike normal

86 strength concrete, the values of $G_{F}$ for high-strength concrete have been found to

87 be sensitive to the aggregate type (Zhou et al. 1995; Xiao et al. 2004). Other

88 results for high-strength concrete show that $K_{I C}$ increases as the w/b ratio

89 decreases (Ince and Alyamac 2008). Thus, the w/b ratio and properties of the

90 aggregate both control the compressive strength and influence the fracture

91 behaviour of high-strength concrete. Hence, for simplicity, compressive strength

92 is widely used as an input parameter for calculating $G_{F}$ along with the maximum

93 aggregate diameter (Committee Euro-International du Beton 1993; Bazant and

94 Becq-Giraudon 2002). However, the results of Chen and Liu (2004), and Ackay et

95 al. (2012), indicate that both $K_{I C}$ and $G_{F}$ of normal and high-strength concretes

96 are influenced by the volume fraction of coarse aggregate. This is because the

97 dissipated fracture energy is dependent on the physical characteristics of the crack

98 path through the concrete. A tortuous crack path, with associated micro-cracking,

99 crack-bridging and aggregate interlocking will result in the absorption of more

100 energy than a smooth crack path. The path of a crack during fracture will be

101 influenced by the coarseness of internal random grain structure of the concrete, $\lambda$,

102 which is itself dictated by aggregate grading (Amparano and Roh 2000). This

103 suggests that aggregate grading can influence the fracture behaviour of concrete.

105 In high-strength concrete, the propagation of cracks, whether passing round or

106 through the aggregates, is dominated by the quality and distribution of the various

107 size of aggregates (Issa et al. 2003). When using high-quality aggregates, the

108 aggregate grading (and associated particle-size distribution) is a significant factor

109 in controlling the coarseness of the internal random grain structure of concrete and

110 influences the crack path that develops during the fracture process. Chen and Liu 
111 (2004), and Ackay et al. (2012) have noted that whilst the volume fraction of

112 coarse aggregate is thought to influence both $K_{I C}$ and $G_{F}$ of concrete there remains

113 a lack of experimental evidence in this area. Since the volume fraction of coarse

114 aggregate reflects the aggregate size distribution, understanding the fracture

115 behaviour of concrete based on its aggregate size distribution is important.

116 Therefore, the objectives of this study were to investigate the role of aggregate

117 size distribution and w/b ratio on the fracture behaviour of high-strength concrete

118 and resulting values of $K_{I C}$ and $G_{F}$.

\section{Experimental setup}

\section{$120 \quad 2.1$ Materials}

121 Flinty river gravel from the Thames Valley river was used for coarse aggregate

122 with sizes in the range of $5 \mathrm{~mm}$ to $16 \mathrm{~mm}$. The fine aggregate was a natural river

123 gravel of size ranging from $4 \mathrm{~mm}$ down to $0.30 \mathrm{~mm}$. A CEM Type I with a

124 specific surface area of $338 \mathrm{~m}^{2} / \mathrm{kg}$ was employed in the mix combining additional

125 Pulverized Fuel Ash (Fly Ash) conforming to BS EN450-S category B. A slurry-

126 based silica fume was also involved in some of the concrete mixes. A super-

127 plasticiser was employed to allow appropriate workability of the fresh concrete.

129 The concrete mix proportions of each material used are shown in Table 1. A total

130 of six different concrete mixes were produced employing three aggregate grading

131 curves, designated as 'A', 'B' and ' $C$ ', see Figure 1 . To achieve the appropriate

132 grading a batch of the as-received aggregate was sieved into its component

133 fractions and the required amount of each fraction was then recombined. Two

134 total water to binder $(\mathrm{w} / \mathrm{b})$ ratios of 0.20 (equivalent to a free w/b ratio of $0.17 \pm$ 
1350.02 ) and 0.30 (equivalent to a free water/binder ratio of $0.23 \pm 0.01$ ) were used,

136 and were designated as ' 1 ' and '2' respectively, see Table 1 . Thus, mix

137 'A1'indicates a mix with aggregate grading type 'A' and a total w/b ratio of 0.20 .

138 Table 1 Mix proportions of the six concrete mixes tested.

139

\begin{tabular}{|c|c|cc|c|c|c|c|c|}
\hline \multirow{2}{*}{ Mix } & \multirow{2}{*}{ w/b* } & \multicolumn{7}{|c|}{ Unit weight $\left(\mathrm{kg} / \mathrm{m}^{3}\right)$} \\
\cline { 3 - 7 } & & \multicolumn{2}{|c|}{ Aggregate } & Cement & PFA & $\begin{array}{c}\text { Silica } \\
\text { fume }\end{array}$ & Water & $\begin{array}{c}\text { Super- } \\
\text { plasticiser }\end{array}$ \\
\cline { 3 - 8 } A1 & 0.20 & 1108 & 499 & 547.7 & 76.7 & 54.7 & 135.9 & 2.64 \\
A2 & 0.30 & 1108 & 499 & 679 & - & - & 203.7 & 1.61 \\
B1 & 0.20 & 1552 & 54 & 547.7 & 76.7 & 54.7 & 135.9 & 2.01 \\
B2 & 0.30 & 1552 & 54 & 679 & - & - & 203.7 & 1.42 \\
C1 & 0.20 & 1322 & 284 & 547.7 & 76.7 & 54.7 & 135.9 & 2.27 \\
C2 & 0.30 & 1322 & 284 & 679 & - & - & 203.7 & 1.50 \\
\hline
\end{tabular}

140 *Total water/binder ratio

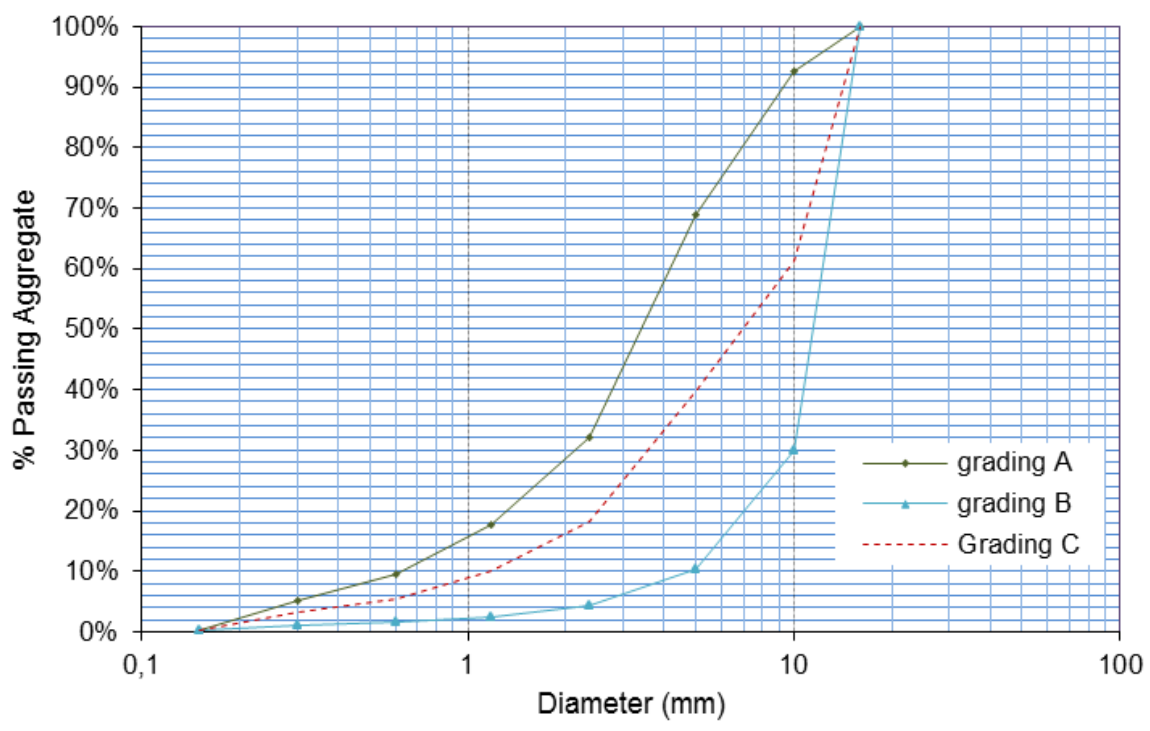

142 Fig.1 Aggregate grading curves for types 'A', 'B', and ' $C$ '.

143 It is well established that the workability of fresh concrete, as measured by its

144 consistence, has a profound effect on the ease of compaction of the material and

145 that incomplete compaction can adversely affect the properties of the resulting

146 hardened concrete (Neville and Brook 1990). As a consequence, the consistence

147 of all the mixes used in this study was kept constant, the target slump value for all

148 the mixes was $120 \pm 20 \mathrm{~mm}$ (equivalent to a consistence class S3 as prescribed by 
149 ENV 206, Part 1: 2000). This was achieved by varying the quantity of super-

150 plasticiser in each mix, Table 1 . Since the aggregate to binder ratio is also known

151 to affect the concrete properties, it is kept constant for all mixes used in this study.

\section{$152 \quad 2.2$ Specimens and Test Setup}

153 At least nine $100 \times 100 \times 100 \mathrm{~mm}$ cubes were tested to determine the average

154 compressive strength of the hardened concrete, following BS EN 12390: Part

155 3(2000). The fracture behaviour of the hardened concrete was determined using

$156100 \times 100 \times 850 \mathrm{~mm}$ beam specimens tested in three-point bend (TPB) following

157 RILEM TC 50-FCM (1985). All of the specimens were de-moulded

158 approximately 24 hours after casting and cured under water at $22 \pm 2{ }^{\circ} \mathrm{C}$ for 30

159 days prior to testing.

161 Figure 2 shows the dimension of the notched beam specimen for the associated

162 three-point bend test arrangement. The depth (d), the width (t) and the total length

163 (L) of the beam was 100, 100, and $850 \mathrm{~mm}$ respectively with a support span (S) of

$164800 \mathrm{~mm}$. A notch depth $\left(\mathrm{a}_{0}\right)$ of $25 \mathrm{~mm}$ and width of $2.5 \mathrm{~mm}$ was created in all of

165 the specimens prior to testing.

167 The TPB test was carried out using a closed-loop servo-hydraulic testing machine

168 with a maximum load capacity of $600 \mathrm{kN}$. The applied load was measured using 169 a $10 \mathrm{kN}$ load cell. The loading rate was controlled by applying a vertical

170 displacement of $0.01 \mathrm{~mm} / \mathrm{s}$, following the methodology developed by Zhang at al.

171 (2009). A calibrated linear variable differential transducer (LVDT) was employed

172 to measure the vertical deflection of the beam at the loading point. A clip gauge

173 was used to quantify the crack mouth-opening displacement, Figure 2. 


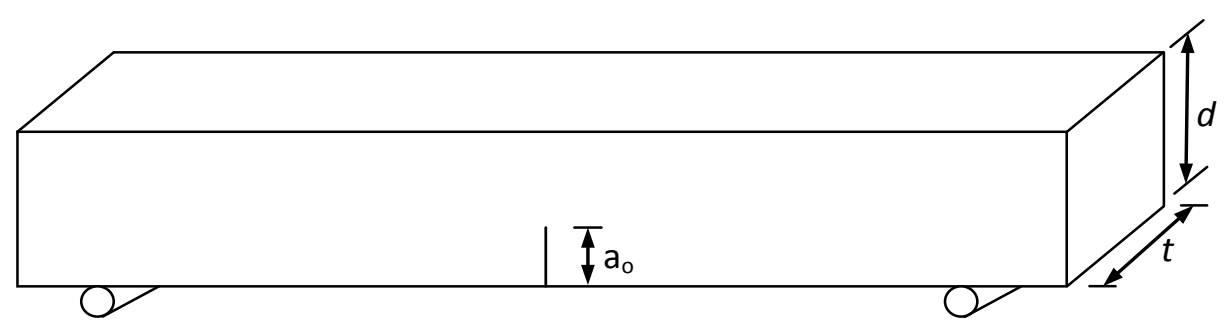

184 Fig. 2 Geometry of specimen and test set up showing detail of clip gauge 185 attachment

\section{Concrete properties}

187 The measured values of slump of the fresh concrete and the compressive strength

188 of the hardened concrete, tested at 30 days, are presented in Table 2. It can be seen

189 that the average slump of all the mixes were controlled within the target range

$190120 \pm 20 \mathrm{~mm}$.

192 The average compressive strength of the concrete mixes with a total w/b ratio of

1930.30 (equivalent to a free water/binder ratio of $0.23 \pm 0.01$ ) ranged from 66-

$19468 \mathrm{MPa}$. The average compressive strength of the concrete mixes with a total w/b

195 ratio of 0.20 (equivalent to a free w/b ratio of $0.17 \pm 0.02$ ) ranged from 85-

$19698 \mathrm{MPa}$. These results are in agreement with the well-known Abrams' law

197 (Mindess and Young 1983) in that the measured compressive strength increases

198 with decreasing w/b ratio. Whilst the w/b ratio is the main factor dictating the 
199 compressive strength of hardened concrete, local changes in the size, shape and 200 distribution of the aggregates within individual test specimens contributes to the 201 measured variability. However, this variability is within normal limits for high 202 strength concrete mixes.

204 Table 2 Slump, mean (30-day) compressive strength and coarseness ratio of concrete mixes

\begin{tabular}{|c|c|c|c|c|c|c|c|}
\hline \multirow{2}{*}{ Mix } & \multicolumn{3}{|c|}{ Slump } & \multicolumn{3}{|c|}{ Compressive strength } & \multirow{2}{*}{$\lambda$} \\
\hline & $\mathrm{mm}$ & $\mathrm{N}$ & S & $\mathrm{MPa}$ & $\mathrm{N}$ & $S$ & \\
\hline A1 & 110 & 4 & 4.4 & 85.2 & 12 & 5.7 & 0.32 \\
\hline B1 & 100 & 4 & 6.4 & 97.6 & 12 & 1.4 & 0.22 \\
\hline C1 & 115 & 3 & 6.3 & 94.8 & 9 & 2.6 & 0.25 \\
\hline A2 & 100 & 4 & 6.8 & 68.2 & 12 & 3.6 & 0.32 \\
\hline B2 & 120 & 3 & 5.5 & 66.0 & 9 & 2.9 & 0.22 \\
\hline $\mathrm{C} 2$ & 130 & 3 & 7.8 & 68.4 & 9 & 0.8 & 0.25 \\
\hline
\end{tabular}

$205 \mathrm{~N}=$ number of test specimens, $\mathrm{S}=$ Standard deviation of sample, $\lambda=$ coarseness of internal random 206 grain structure.

2084 Coarseness of internal random grain structure $(\lambda)$, 209 and fracture characteristic ( $K_{I C}$ and $\left.G_{F}\right)$ of concrete

210 The coarseness of the internal random grain structure of the hardened concrete, $\lambda$,

211 is presented in Table 2, and the derived fracture characteristics of the concrete, i.e.

$212 K_{I C}$ and $G_{F}$, are presented in Table 3 and these are considered in more detail in the 213 following sub-sections. 


\section{4.1. Coarseness of internal random grain structure of concrete}

216 According to Amparano and Roh (2000) the coarseness of the internal random

217 grain structure of concrete, $\lambda$, is defined as:

$218 \quad \lambda=\frac{1}{\mathrm{D}_{\mathrm{ave}}\left(1-\mathrm{v}_{\mathrm{a}}\right)}$

219 where, $D_{a v e}$, is the average diameter of the aggregate particles, and $V_{a}$ is the

220 volume fraction of the coarse aggregate (above $4 \mathrm{~mm}$ ) calculated from the mix

221 design parameters of this study (Table 1) and the grading curves shown in Figure

222 1. It can be seen from Eq. (1) that the value of $\lambda$ is dependent on both the volume

223 fraction and average diameter of coarse aggregate and is considered to be an

224 important factor affecting the dissipated fracture energy in concrete. The effect of 225 the aggregate grading used in the concrete mix tested in this study produced 226 different values of $\lambda$, i.e. 'B' - low $(\lambda=0.22)$, 'C' - medium $(\lambda=0.25)$ and, 'A' 227 high $(\lambda=0.32)$, see Table 2.

228

\section{$229 \quad 4.2$ Fracture energy}

230 One parameter that has been widely used to characterise the fracture behaviour of 231 brittle composite materials such as concrete is the fracture energy, $G_{F}$. In this

232 study, values of $G_{F}$ (for each specimen) were calculated from the corresponding 233 load vs mid-span deflection curve, Figures 3(a) and 3(c). By following the 234 recommendations of RILEM TC50-FCM (RILEM 1985) it was possible to 235 account for the effects of the self-weight of the beam:

$$
G_{F}=\frac{W_{0}+m_{\mathrm{g}} \delta_{0}}{\left(d-\mathrm{a}_{0}\right) t}
$$


237 where, $G_{F}$ is the total fracture energy, $W_{0}$ is the area under the load-deflection

238 curve, $m$ is the total mass of specimen between supports, $g$ is the gravitational 239 constant, $\delta_{o}$ is the deflection at failure, $d$ is the height of the sample, $\mathrm{a}_{o}$ is the

240 depth of the notch and $t$ is the width of the sample. Values of the mean fracture

241 energy and standard deviation for the samples tested are presented in Table 3.

243 The fracture energy dissipated during the failure process of concrete can be 244 related to the crack opening, which drives the crack forward. This was monitored 245 by the load vs crack mouth-opening displacement (CMOD) curves, Figures 3(b) 246 and 3(d). These were used to assist analysis of the crack-opening behaviour in the 247 post- peak stress regime.

\section{$249 \quad 4.3$ Critical stress intensity factor $(K / c)$}

250 In considering the tensile fracture of concrete it is important to consider the role of

251 inherent defects, such as cracks, in limiting the stress that can be supported by a 252 given section of material. In the case of brittle ceramic materials, such as concrete, 253 the role of cracks can be successfully modeled on the basis of linear elastic 254 fracture mechanic-LEFM (Shah and Ahmad 1994). This approach assumes that a 255 suitably oriented crack within the material will start to propagate when the (mode

256 I) stress intensity factor $K_{I}$, at the crack tip exceeds the critical stress intensity

257 factor, $K_{I C}$, which is also know as the fracture toughness (Zhang and Xu 2011). At 258 its simplest $K_{I}$ can be considered to be a measure of the force tending to cause fast 259 fracture whilst $K_{I C}$ is a material property, like stiffness and Poisson's ratio that is a 260 measure of the materials resistance to crack growth. In a brittle material 261 containing a crack (of given size) and subject to an externally applied stress fast 
262 fracture will not occur provided that $K_{I}<K_{I C}$. Determination of the appropriate

263 stress intensity factor is complicated by the fact that $K_{I}$ is a function of the crack

264 length, the local (and global) geometry, the value and mode of the externally

265 applied load and associated boundary conditions (Shah et al. 1995).

267 In this study the LEFM approach has been used to analyse the effect of the three

268 different aggregate size distributions on the fracture characteristic of high-strength

269 concrete tested in three-point bend up to the peak stress. The values of $K_{I C}$ for the

270 individual test samples was carried out following the RILEM TC89-FMT

271 (RILEM 1990):

$272 \quad K_{I C}=\frac{3\left(P_{c}+0.5 W\right)\left[s\left(\pi a_{\partial}\right)^{0.5} g\left(\frac{a_{C}}{d}\right)\right]}{2 d^{2} t}$

273 in which,

$$
g\left(\frac{a_{c}}{d}\right)=\frac{1.99-\left(\frac{a_{C}}{d}\right)\left(1-\frac{a_{C}}{d}\right)\left[2.15-3.93\left(\frac{a_{c}}{d}\right)+2.70\left(\frac{a_{C}}{d}\right)^{2}\right]}{\sqrt{\pi}\left[1+2\left(\frac{a_{c}}{d}\right)\right]\left[1-\left(\frac{a_{c}}{d}\right)\right]^{\frac{\pi}{2}}}
$$

276 where, $P_{c}$ is the critical maximum load, $W$ is the beam's self-weight, $S$ is span of

277 specimen, $a_{c}$ is the critical effective elastic crack length, $d$ is the specimen depth,

278 and $t$ is the specimen width. The mean, and standard deviation, of the calculated

279 values of $K_{I C}$ are presented in Table 3. 
286
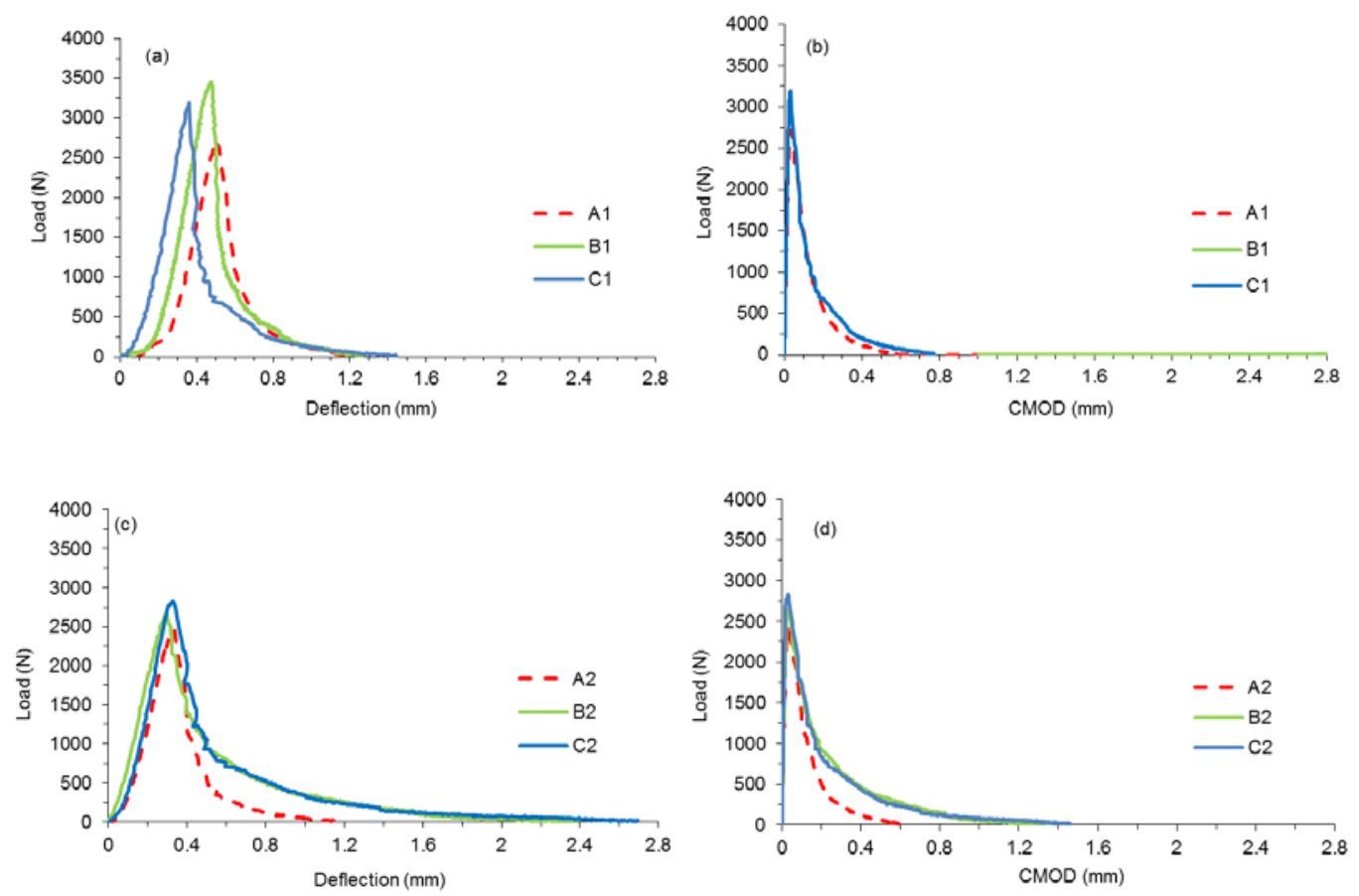

288 Fig. 3 Typical load-deflection and associated load-CMOD curves for concrete

289 with; w/b $=0.2$ (3(a) \& 3(b), and w/b = 0.30 (3(c) \& 3(d).

290

291 Table 3 Fracture energy and critical stress intensity factor for concrete mixes.

\begin{tabular}{lllllll}
\hline & & Number & Mean $G_{F}$ & $\mathrm{~S}$ & Mean $K_{I C}$ & $\mathrm{~S}$ \\
\cline { 6 - 7 } Mix & w/b & of & N/m & $\mathrm{N} / \mathrm{m}$ & MPa.m $^{1 / 2}$ & MPa.m \\
& ratio & & & & & \\
& & samples & & & & \\
\hline A1 & 0.2 & 12 & 93.8 & 9.1 & 0.99 & 0.07 \\
B1 & 0.2 & 12 & 149.9 & 10.6 & 1.24 & 0.11 \\
C1 & 0.2 & 9 & 126.7 & 14.1 & 1.26 & 0.12 \\
A2 & 0.3 & 12 & 85.1 & 10.4 & 0.78 & 0.05 \\
B2 & 0.3 & 9 & 146.5 & 13.3 & 0.93 & 0.11 \\
C2 & 0.3 & 9 & 134.3 & 11.2 & 0.71 & 0.09 \\
\hline
\end{tabular}




\section{Discussion}

\section{$294 \quad 5.1$ Effect of aggregate size distribution}

295 According to Hillerborg and Modeer (1976) the pre-peak tensile response of

296 concrete can best be assessed by examining the stress-strain relationship of the

297 material whilst the post-peak fracture behaviour, or "softening term", can be most

298 accurately assessed by investigating the stress-crack opening curve. In this study 299 both approaches have been employed to help further elucidate the role of 300 aggregate size distribution on the fracture behaviour of both normal and high301 strength concrete.

302

303 The values of $G_{F}$ are dependent on the shape and form of the softening curve 304 making comparisons between samples of the same material and between batches 305 of different materials complicated. As a consequence, normalised stress 306 (Stress/Peak Stress) vs deflection curves were used in the analysis of the post307 peak fracture behaviour of the concrete mixes tested. Figure 4(a) compares the 308 typical deflection and CMOD response obtained for the high-strength concrete 309 mixes A1, B1 and C1 (w/b ratio = 0.2). 

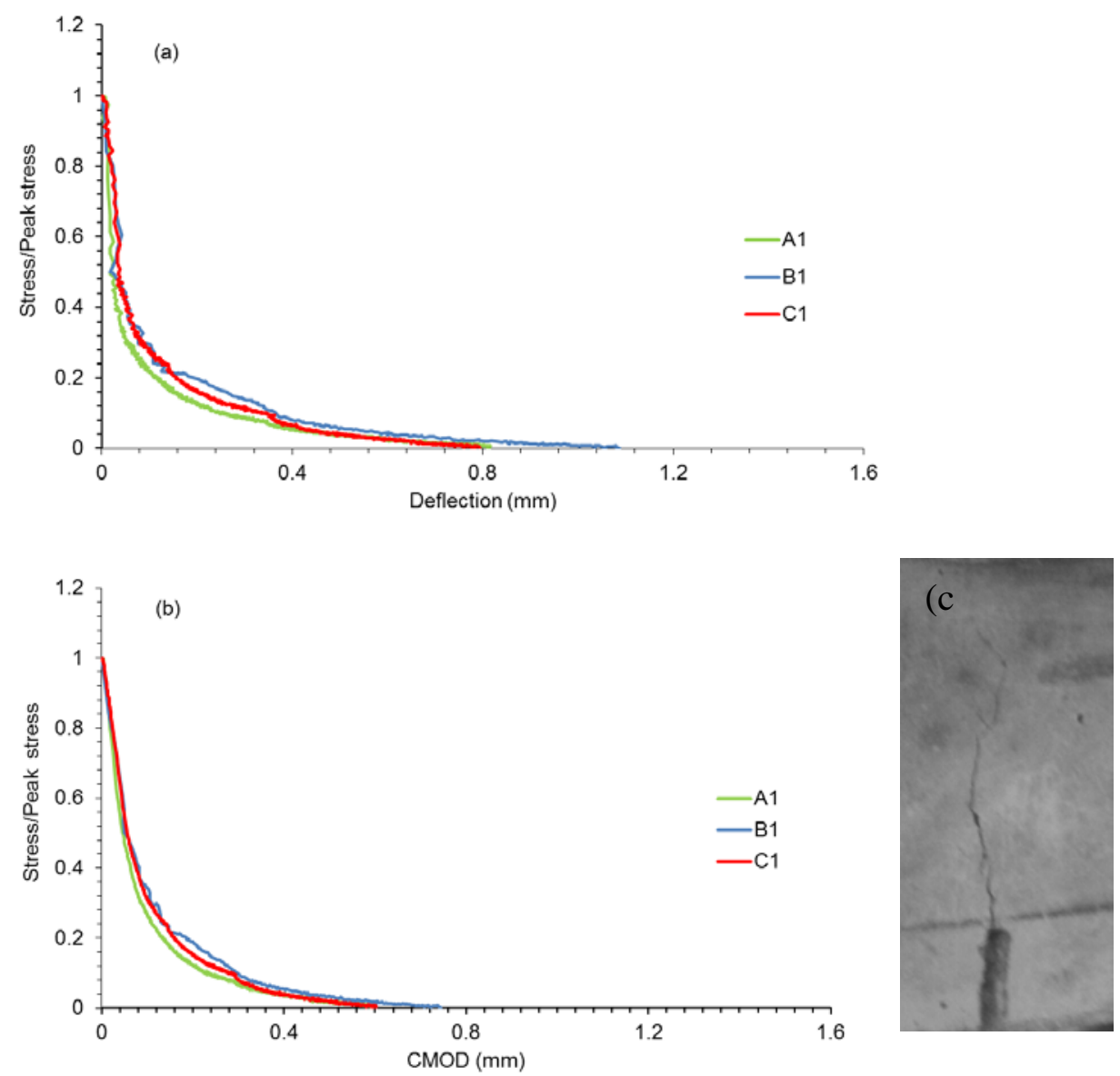

312 Fig. 4 Softening response of three point bending test of concrete with w/b ratio of

3130.20 (a) post-peak stress-deflection curve (b) post-peak stress-CMOD curve (c)

314 crack path of specimen

315 It can be seen that there is little difference in the curves obtained for the three

316 aggregate gradings suggesting that similar processes are at play although the

317 contribution to the total energy absorbed may be different. Indeed it is interesting

318 to compare the fracture energy obtained for mixes B1, C1 and A1 (ranked in

319 terms of their grain size distribution), which yields the values of $G_{F}$ of 149.9,

320126.7 and $93.8 \mathrm{~N} / \mathrm{m}$ for $\lambda$ 's of $0.22,0.25$ and 0.32 respectively, see Tables $2 \& 3$

321 and Figure 6(b). Hence for the high-strength concrete, reduction of coarser

322 aggregate sizes in the mix (represented by an increase in $\lambda$ value) is associated

323 with a significant reduction in the measured fracture energy. This result is in line 
324 with, and confirms, previously published results (Chen and Liu 2004). The values

325 of $G_{F}$ obtained for these mixes may be compared with the measured values of $K_{I C}$

326 of 1.24 (B1), 1.26 (C1) , and 0.99 (A1) MPa.m ${ }^{1 / 2}$ respectively for the same

327 samples, Table 3 . This suggests that the critical stress intensity factor to initiate

328 crack growth is relatively insensitive to the internal random grain structure of

329 concrete, albeit slightly higher for higher proportions of coarse aggregates in the 330 mix, Figure 6(a).

331

332 The above results may be compared with those for mixes A2, B2 and C2, Figure 333 5(a). For these concretes, which have a w/b ratio of 0.3 , the normalised curves

334 obtained demonstrate both a greater variation with the change in $\lambda$ and a 335 somewhat slower rate of decay of normalised stress per unit deflection than seen 336 in Figure 4(a). This suggests that the aggregate size distribution is influencing the 337 post-peak fracture behaviour in a different way to that of the higher strength 338 mixes. Again it is interesting to compare the fracture energy obtained for these 339 mixes when ranked in terms of the grain size distribution, i.e. B2, C2 and A2, 340 which yields values of $G_{F}$ of $146.5,134.3$ and $85.1 \mathrm{~N} / \mathrm{m}$ respectively. These 341 values of $G_{F}$, which are in close agreement with those for mixes A1, B1, and C1

342 (see Table 3), confirm the observation that reducing the coarser grain size in the 343 mix (increasing $\lambda$ ) is associated with lower fracture energy. That is to say the 344 degree of coarseness of internal random grain structure plays a role in the energy 345 absorption process during the fracture of hardened concrete. As with the higher 346 strength mixes measured values of $K_{I C}$ are, when compared to $G_{F}$, relatively 347 insensitive to changes in $\lambda$, see Figure $6(a)$. The influence of w/b ratio on both $G_{F}$ 348 and $K_{I C}$ is discussed in section 5.2. 


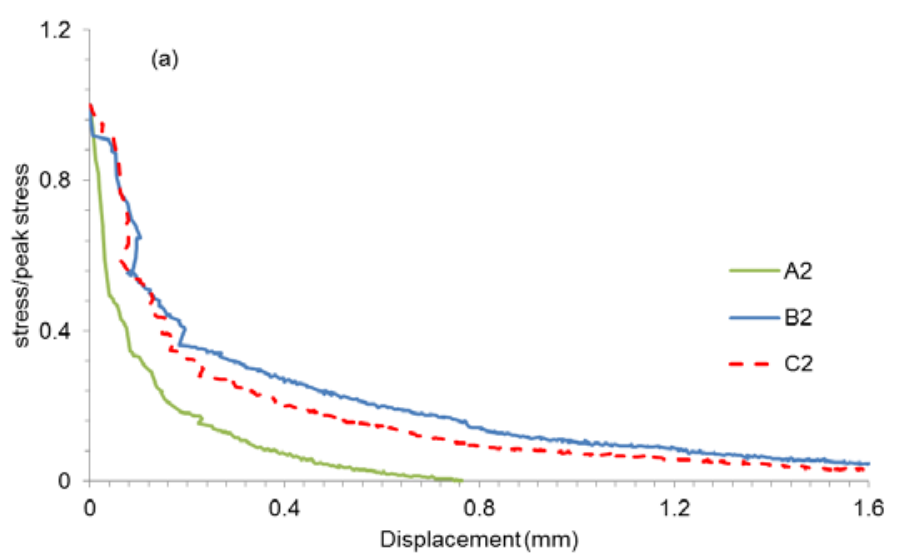

349
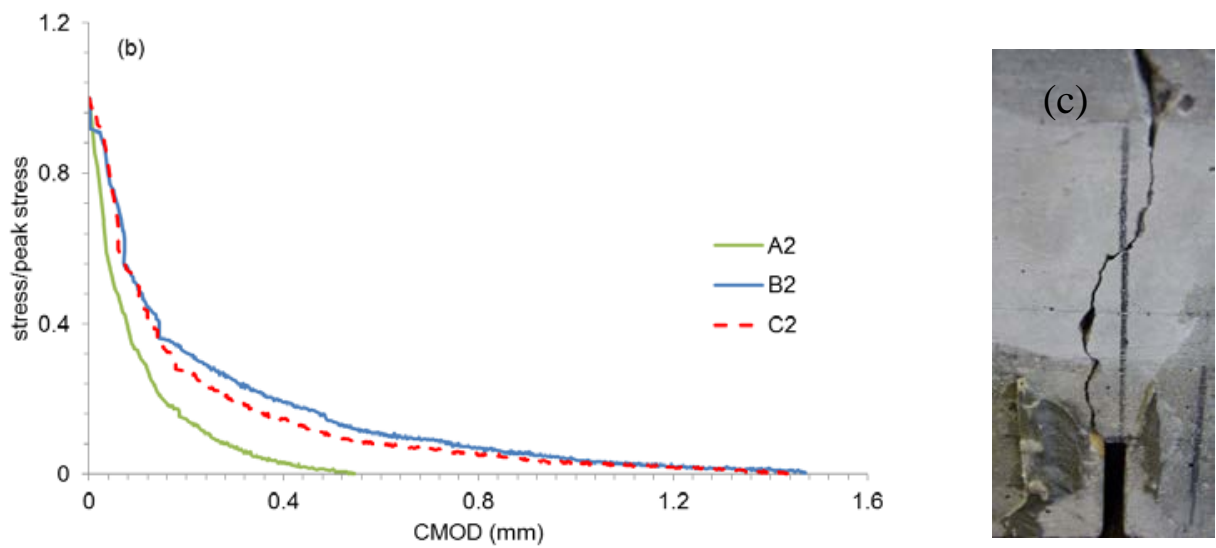

351 Fig. 5 Softening response of three point bending test of concrete with w/b ratio of

3520.30 (a) post-peak stress-deflection curve (b) post-peak stress-CMOD curve (c)

353 crack path of specimen

355 Having established the impact of $\lambda$ on both $G_{F}$ and $K_{I C}$ it is useful to consider 356 factors which may be contribute to the overall fracture process. The interfacial 357 zone properties and aggregate properties such as size distribution and surface 358 texture can play an important role in resisting crack opening. Since the aggregate 359 used in these experiments was from a single source, it has been assumed that the 360 effect of aggregate surface texture can be safely ignored. Altering the w/b ratio 361 has the potential to change the stiffness (and strength) of the interfacial zone that 362 exists between the aggregate and the cement matrix. If the strength of the 
363 aggregate particles is more than that of the interfacial zone matrix, the aggregate

364 particles can act as crack growth arresters in the fracture process (Giaccio and

365 Zerbino 1998). Other toughening mechanisms such as micro-crack shielding and

366 particle bridging can also assist in the increase of the fracture resistance of

367 concrete when the aggregate has not failed, i.e. the crack propagates only within

368 the interfacial zone or through the cement paste. For such a case, the crack path

369 would be expected to show a strong correlation with $\lambda$, i.e. higher coarseness of

370 internal grain structure of concrete would lead to a more tortuous crack path and

371 vice versa. This mechanism could explain the longer "tail” in the post-peak stress

372 vs displacement curve of Figures 5(a) which was obtained with the lower strength

373 concrete (i.e. higher w/b ratio). In contrast, if the strength of the aggregate is less

374 than that of the interfacial zone matrix, the crack becomes able to propagate

375 through the aggregate particles, and is thus less sensitive to $\lambda$. Such behaviour

376 would be expected to produce a relatively straight crack path (Figure 4 (c)) and

377 smaller "tail” in the post-peak curve such as the one shown in Figure 4(a) for the

378 higher strength concrete tested here. Hence, the fracture characteristic of high

379 strength concrete can be assessed on the basis of the fracture parameters and the

380 slope of the post-peak curves.

381

382 It should be remembered that a crack will only propagate if the stress intensity at

383 the crack tip is greater than $K_{I C}$. The propagation of a growing crack during a

384 three-point bend test is related to the crack opening, which can be analysed 385 through normalised stress versus CMOD curves, Figures 4(b) and 5(b). Although

386 this is a qualitative analysis, it suggests that whilst internal random grain structure

387 influences the crack opening in the high w/b ratio concrete (Fig. 5b), its affect at 
388 low w/b ratios is small (Fig. 4b). This suggests that the influence of grain size

389 distribution on the crack opening decreases with concrete strength, see section 5.2.

390

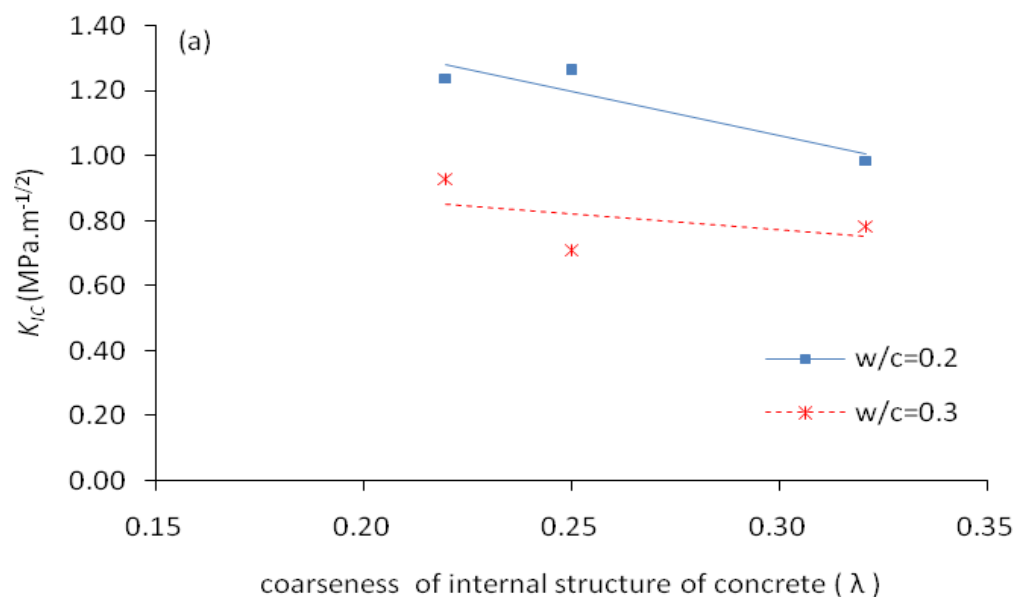

391

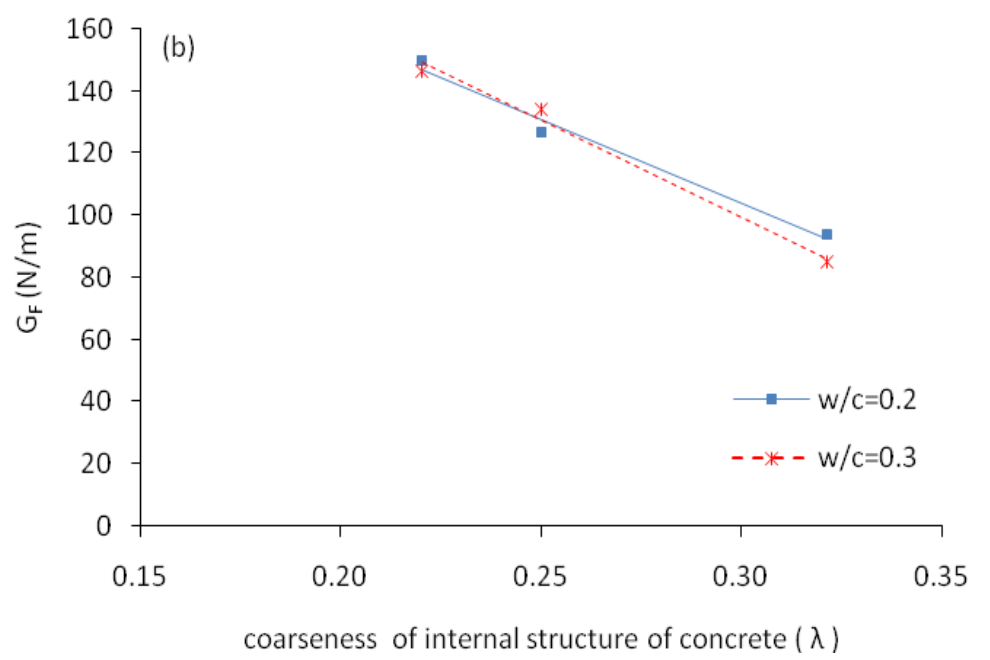

392

393 Fig. 6 The effect of coarseness of internal structure of concrete on (a) the stress

394 intensity factor $\left(K_{I C}\right)$ and, (b) fracture energy $\left(G_{F}\right)$

395 It can also been seen from Figure 4 and 5 that the level of ductility varies

396 considerably for the beams with different aggregate size distribution and w/b ratios.

397 Ductility ratio for the beams is computed to analyze this further and is shown in Table

398 4. Ductility ratio is taken as the ratio of the deflection of beam at failure to deflection

399 of beam at the yield point (Rao et al., 2010). The Table clearly demonstrates that the 
401 exhibited by high strength concrete.

402

\begin{tabular}{|l|c|c|c|c|c|c|}
\cline { 2 - 7 } \multicolumn{1}{c|}{} & \multicolumn{7}{c|}{ Gradation of aggregate } \\
\cline { 2 - 7 } \multicolumn{1}{c|}{} & $\mathrm{A} 1$ & $\mathrm{~B} 1$ & $\mathrm{C} 1$ & $\mathrm{~A} 2$ & $\mathrm{~B} 2$ & $\mathrm{C} 2$ \\
\hline $\begin{array}{l}\text { yield deflection } \\
(\mathrm{mm})\end{array}$ & 0.5 & 0.41 & 0.39 & 0.33 & 0.28 & 0.33 \\
\hline $\begin{array}{l}\text { max deflection } \\
(\mathrm{mm})\end{array}$ & 1.20 & 1.47 & 1.42 & 1.17 & 2.34 & 2.68 \\
\hline $\begin{array}{l}\text { Ductility } \\
\text { ratio of } \\
\text { beam }\end{array}$ & $\mathbf{2 . 4}$ & $\mathbf{3 . 6}$ & $\mathbf{3 . 6}$ & $\mathbf{3 . 6}$ & $\mathbf{8 . 4}$ & $\mathbf{8 . 1}$ \\
\hline
\end{tabular}

403

5. 2 Effect of water/binder ratio

404 Figure 7 shows the effect of w/b on the measured compressive strength, $f_{c}$, critical 405 stress intensity factor, $K_{I C}$, and fracture energy, $G_{F}$ of the six concrete mixes 406 tested.

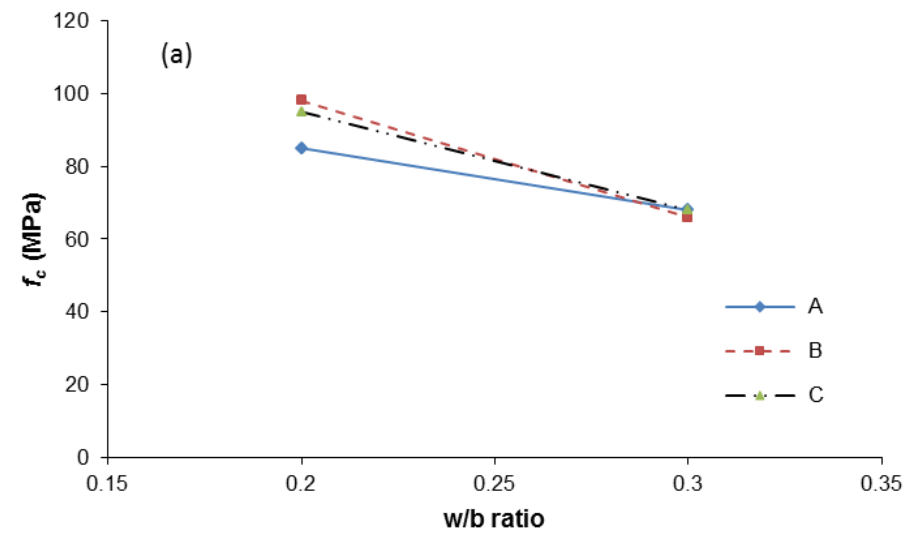

407

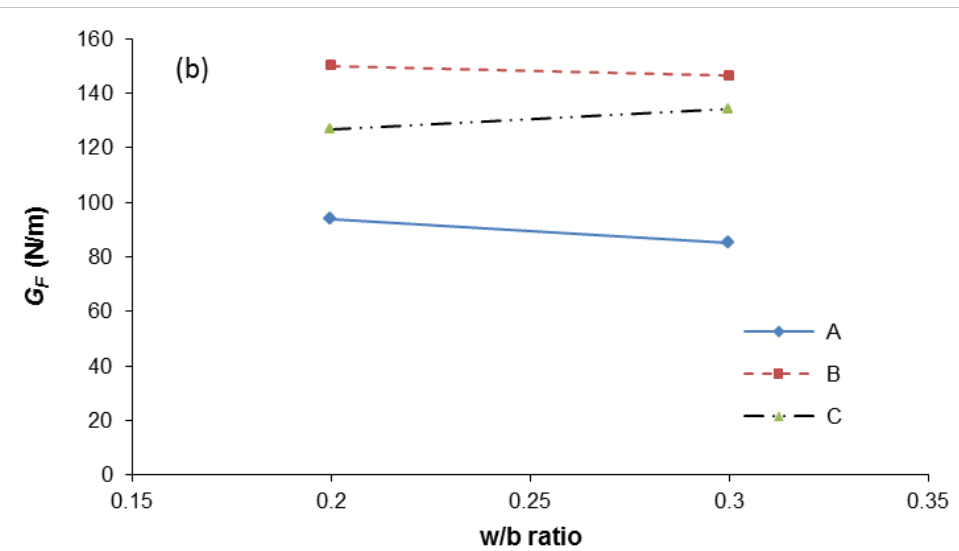




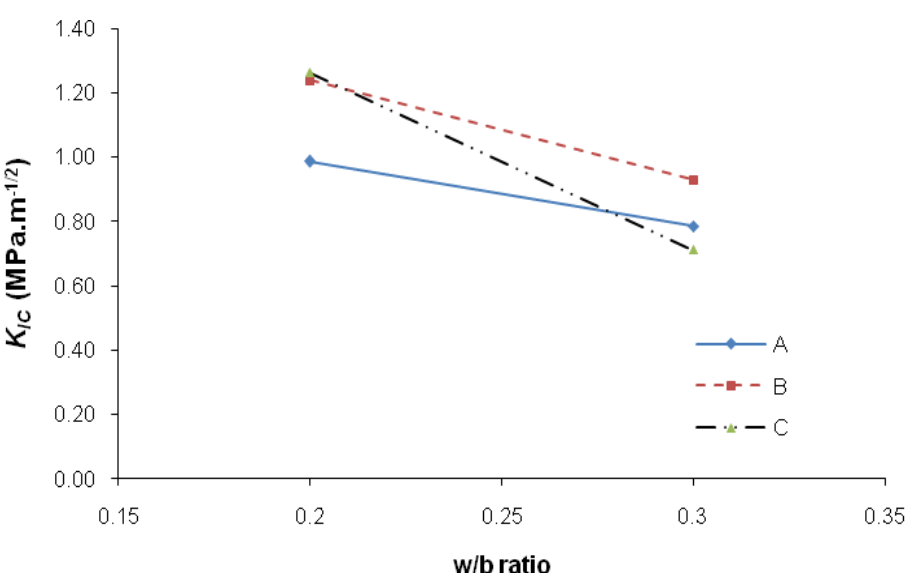

410 Fig. 7 The effect of w/b ratio on (a) compressive strength, (b) fracture energy,

411 and(c) critical stress intensity factors

413 As might be expected $f_{c}$ was found to decrease as the $\mathrm{w} / \mathrm{b}$ ratio increased, Figure $4147(a)$. Similarly $K_{I C}$ sensibly decreased with increasing w/b ratio, Figure7(c). In 415 contrast $G_{F}$ was found to be insensitive to w/b ratio, Figure 7(b). This behaviour 416 reflects the result of the hydration process (Neville and Brook 1990) in that the 417 porosity level in the cement paste is related to the amount water in the mix which, 418 in turn, dictates the bond strength between the aggregate and the cement paste. 419 Moreover, supplementary cementitious materials, such as the PFA incorporated in 420 the high strength mixes used here, contribute by reacting with free calcium 421 hydroxide in the cement paste and induces in improvement in the matrix strength 422 (Köksal and Altun 2008). At the same time unhydrated particles of supplementary 423 cementitious materials will, by filling void space in the bulk paste, reduce the 424 porosity of paste and help the formation of a denser aggregate/cement interfacial 425 zone. Where the stiffness of interfacial zone and aggregate are similar, then 426 aggregate grading, which influences the bonding surface area and density of 427 concrete, can play an important role in distributing stress in the material and hence 428 influence the initiation of cracks. Therefore, w/b ratio and aggregate grading are 
429 factors influencing the quality of the interfacial zone. Consequently, the reduction

430 of w/b ratio of concrete from 0.30 to 0.20 increases $K_{I C}$ by $\approx 26 \%$ and $\mathrm{fc}$ by a

431 similar amount, $\approx 23 \%$. At the same time, the measured values of $G_{F}$ were found

432 to essentially independent of w/b within the accuracy of the measurements. This is

433 thought to be because, as elaborated in Section 5.1, the aggregate grading affects

434 the dissipated fracture energy of concrete. Thus, $G_{F}$ is dependent on the crack path

435 and is influenced primarily by the quality of aggregate, which was kept constant,

436 and the aggregate size distribution, which was varied.

438 The relationship between the measured fracture energy, $G_{F}$, and $f_{c}$, for 439 compressive strength more than $60 \mathrm{MPa}$ is shown in Figure 8, along with 440 published data taken from Bazant and Becq-Giraudon (2002) for normal strength

441 concrete $\left(\mathrm{f}_{\mathrm{c}}<50 \mathrm{MPa}\right)$ with the same value of $\lambda(=0.25)$.

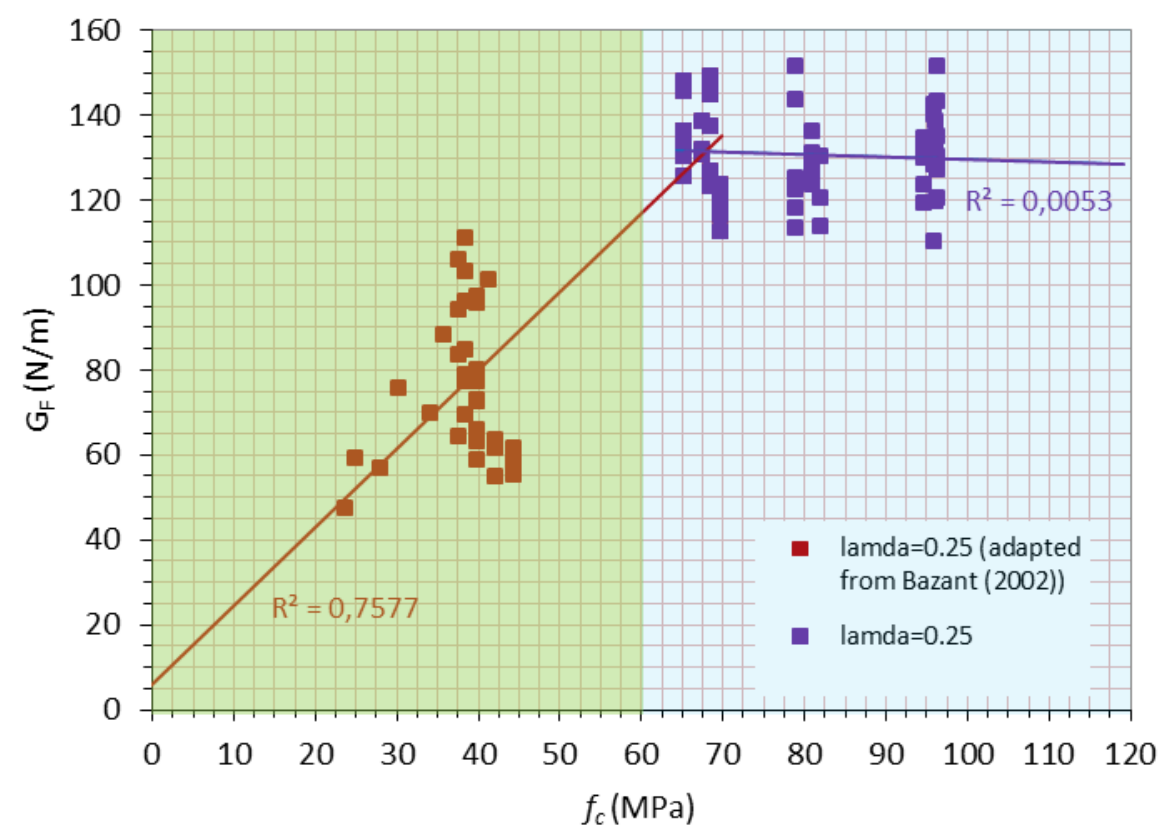

443 Fig. 8 Effect of compressive strength on the $G_{F}$ of concrete 
445 Although the experimental data shows some scatter, it can be seen that initially $G_{F}$

446 increases linearly, and a regression on the trend line yields an $f_{c}, \mathrm{R}^{2}=0.758$. This

447 relationship holds where the concrete strength is below $\approx 60-70 \mathrm{MPa}$. However,

448 where the strength of the concrete is above this value, $G_{F}$, remains at around 130

$449( \pm 20) \mathrm{N} / \mathrm{m}$ and appears unaffected by any increase in $f_{c}$, indeed a regression on

450 the trend line yields an $\mathrm{R}^{2}=0.005$ which suggests that the two variables are not

451 correlated. Given that these results are for concrete manufactured with the same

452 value of $\lambda$, this behaviour is not related to any change in the coarseness of internal

453 random grain structure. Thus, for the normal strength concrete mixes $\left(f_{c}<60 \pm 5\right.$

$454 \mathrm{MPa}$ ), where the fracture path is dominated by aggregate cement de-bonding (a

455 more tortuous crack path exists), $G_{F}$ increases with $f_{c}$ (and hence w/b ratio) due to

456 the improved strength of both the aggregate/cement bond and the cement matrix

457 itself. When $f_{c}$ exceeds $\approx 60 \pm 5 \mathrm{MPa}$ then the aggregate/cement bond strength is

458 sufficient that the fracture path can pass through the aggregate particles. When

459 this transition occurs the fracture path becomes dominated by aggregate failure

460 and as a consequence $G_{F}$ is limited by the strength of the aggregate despite the

461 compressive strength of the concrete, $f_{c}$, continuing to increase. Therefore, the

462 maximum value of $G_{F}$ for a given high strength concrete will be limited by the 463 strength of the aggregate.

\section{Conclusions}

466 The aim of this paper was to investigate the effect of aggregate size distribution

467 (induced by aggregate grading) on the fracture behaviour of high-strength 468 concrete. Based on a qualitative analysis of the post-peak softening curve 
469 behaviour and a quantitative analysis of the measured fracture energy $\left(G_{F}\right)$ and 470 critical stress intensity factor $\left(K_{I C}\right)$ the following conclusion can be drawn:

471 1. The compressive strength and critical stress intensity factor of the high-

2. The size distribution of the aggregate, measured using the coarseness of internal random grain structure of the concrete, $\lambda$, has a significant influence on the fracture energy of high strength concrete. Changing $\lambda$ from 0.32 to 0.22 resulted in a $50 \%$ increase in measured values of $G_{F}$.

3. The critical stress intensity factor, $K_{I C}$, is relatively insensitive to the aggregate size distribution; however, higher proportion of coarser grain size tends to increase the $K_{I C}$.

4. On the basis of the measured values of $G_{F}$ and the $K_{I C}$, the aggregate size distribution and w/b ratio were found to influence the level of ductility exhibited by high strength concrete.

5. The maximum value of $G_{F}$ for a high strength concrete will be limited by the strength of the aggregate.

487 The fracture parameters obtained in these experiments enrich the factors which 488 influence the fracture behaviour of high-strength concrete and can be used to 489 further refine predicted fracture energy formula used in developing design criteria.

491 Acknowledgements The authors would like to acknowledge The Higher Education Directorate 492 General, Ministry of National Education, Republic of Indonesia for the financial support for this 493 project, and the University of Surrey for infrastructures, facilities and laboratories. 

and Building Materials 28: 437-443.

499 Amparano F. E., Xi, Y., Roh Y. S. (2000) Experimental study on the effect of aggregate content on 500 fracture behaviour of concrete. Engineering Fracture Mechanics 67: 65-84.

501 American Concrete Institute (2010) Report on high strength concrete. ACI-363R-10. Farmington 502 Hills, USA.

503 Bazant Z. P. and Becq-Giraudon E. (2002) Statistical prediction of fracture parameters of concrete 504 and implications for choice of testing standard. Cement and Concrete Research 32: 529-556.

505 Chen B. and Liu J. (2004) Effect of aggregate on the fracture behaviour of high strength concrete.

506 Construction and building materials 18: 585-590.

507 Committee Euro-International du Beton (1993) CEB-FIP Model Code 1990. Thomas Telford, UK. 508 CommitteeEuro-International du Beton (2010) CEB-FIP Model Code 2010 (first draft). fib 509 Bulletin 55: Model Code 2010, First complete draft - Volume 1, Lausanne, Switzerland.

510 Elices M. and Rocco C. G. (2008) Effect of aggregate size on the fracture and mechanical 511 properties of a simple concrete. Engineering Fracture Mechanics 75(13): 3839-3851.

512 Giaccio G. and Zerbino R (1998) Failure mechanism of concrete: combined effect of coarse 513 aggregate and strength level. Advance Cement Based Materials 7(2): 41-48.

514 Hillerborg A. A. (1985) Result of three comparative test series for determining the fracture energy $515 G_{F}$ of concrete. RILEM materiaux et Constructions 18(107): 33-39.

516 Hillerborg A. A. and Modeer M. (1976) Analysis of crack formation and crack growth by means 517 of fracture mechanics and finite element. Cement and Concrete Research(6): 773-782.

518 Ince, R. and Alyamac K. E. (2008) Determination of fracture parameters of concrete based on the 519 water-cement ratio. Indian Journal of Engineering \& Materials Sciences 15: 14-22.

520 Issa M. A., Issa M. A. Islam, Md.S., and Chudnovsky, A. (2003) Fractal dimension-a measure of 521 fracture toughness and toughness of concrete. Engineering Fracture Mechanics 70(1): 125-137.

522 Karamloo, M., Mazloom, M., Payganeh, G. (2016) Effects of maximum aggregate size on fracture 523 behaviour of self-compacting light weight concrete. Construction and Building Materials, 123, 524 508-515.

525 Köksal F. F. and Altun F. (2008) Combined effect of silica fume and steel fiber on the mechanical 526 properties of high strength concretes. Construction and Building Materials 78(10): 1875-1880.

527 Königsberger M., Pichler B., and Hellmich, C. (2014) Micromechanics of ITZ-aggregate 528 interaction in concrete Part II: Strength upscaling. J Am Ceram Soc 97(2): 543-551.

529 Mindess S. and Young J. F. (1983) Concrete. Prentice-Hall Inc., Englewood Cliffs, New Jersey, 530 USA.

531 Mihashi H., Nomura N., Niiseki, S. (1991) Influence of aggregate size on fracture process zone of 532 concrete detected with three dimensional acoustic emission technique. Cement and Concrete 533 Research 21(5): 737-744.

534 Neville A. M. and Brook J. J. (1990) Concrete Technolog y.Addison Wesley Longman Ltd, 535 Update revision, UK. 
536 Rao G.A., Vijayanand I., Eligehausen R. (2010) Studies on ductility and evaluation of

537 minimum flexural reinforcement in RC beams. Materials and Structures 41 (4), 759-

$538 \quad 771$

539 RILEM TC89-FMT (1990) Fracture mechanic of concrete test method. Material and Structures 23:

$540 \quad 247-252$.

541 RILEM TC 50-FCM (1985) Determination of the fracture energy of mortar and concrete by means

542 of three-point bend tests on notched beams. Material and Structures 18(106): 285-290.

543 Shah S. P. and Ahmad S. H. (1994) High performance concrete and its applications. Edward

544 Arnold Press Ltd, UK.

545 Shah S. P., Swartz S. E., Ouyang, C. (1995) Fracture mechanic of concrete. John Willey and sons 546 Inc., Canada, USA.

547 Wolinski S., Hordjik D. A., Reinhardt, H.W. and Cornelissen, H.A.W. (1987) Influence of 548 aggregate size on fracture mechanics parameters of concrete. International journal of cement 549 composites and lightweight concrete 9(3): 95-103.

550 Wu K. R., Chen B., Yao, W., and Zhang, D. (2001). "Effect of coarse aggregate type on 551 mechanical properties of high-performance concrete." Cement and Concrete Research 31(10): 552 1421-1425.

553 Xiao J., Schneider H., Donnecke, C., and Konig, G. (2004) Wedge splitting test on fracture 554 behaviour of ultra high strength concrete. Construction and building materials 18(6): 359-365.

555 Zhang X. and Xu S. (2011) A comparative study of five approaches to evaluate double-K fracture 556 toughness parameters of concrete and size effect analysis. Engineering Fracture Mechanics 78(10): $557 \quad 2115-2138$.

558 Zhang X. X., Ruiz G., Yu, R.C. and Tarifa, M. (2009) Fracture behaviour of high strength concrete 559 at wide range of loading rates. International Journal of Impact Engineering 36(10-11): 1204-1209.

560 Zhou F. P., Barr B. I. G., and Lydon, F.D. (1995) Fracture properties of high strength concrete 561 with varying silica fume content and aggregates. Cement and Concrete Research 25(3): 543. 